PROC. OF JSCE,

No. 223, MARCH 1974

\title{
MODEL STUDIES ON THE STRESS DISTRIBUTION AND THE BEARING CAPACITY OF SOIL GROUND
}

\author{
By Koichi AKAI* and Hideo OTSUKI**
}

\section{INTRODUCTION}

The failure pattern of soil ground on which an arbitrary load is applied is generally divided into two types; the general shear failure and the local shear failure. It is considered that such a difference depends mainly on the stress-strain relationship of soil constituting the ground. The general shear failure is occurred in stiff clays and dense sands, whereas soft clays and loose sands undergo the local shear failure. ${ }^{1)}$

Previous theories on the bearing capacity of soil based upon the rigid-plasticity theory mainly treat the general shear failure. The treatment is considered reasonable, if the amount of displacement at the first stage is comparably small so that an abrupt failure can be seen. It is not acceptable, on the other hand, to apply the rigidplasticity theory to the local shear failure, considering the failure mechanism. In this case the theory of bearing capacity based on the elastoplasticity theory is rather preferable.

A series of model studies are performed on the stress distribution and the bearing capacity of soil ground, by using a pretty large model and a universal loading apparatus. In addition the analytical consideration by means of the finite element technique is paid to the behavior of development of the plastic region in the ground due to increase in the load intensity.

\section{EXPERIMENTAL APPARATUS AND TEST PROCEDURE}

\section{(1) Test Pit and Loading System}

The outline of the experimental apparatus is shown in Fig. 1. The test pit used in this work

* Dr. Eng., Professor of Civil Engineering, Kyoto University.

** M.S.C.E., Engineer, Tokyo Electric Power Co., Ltd.

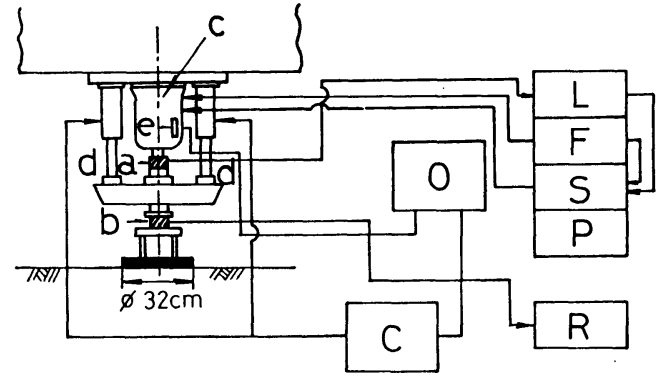

Fig. 1 Loading system; a: load cell for control, b: load cell for measurement, c: cylinder for dynamic load, $\mathrm{d}$ : cylinder for sustained load, e: servo-valve, L: load amplifier, F: function generator, $\mathrm{S}$ : servo-amplifier, $\mathrm{P}$ : pressure source controller, $\mathrm{O}$ : oil pressure source, $\mathrm{C}$ : sustained pressure supporter, R: recorder.

Table 1 Physical properties of soil materials.

\begin{tabular}{l|c|c}
\hline & Sandy loam & Sand \\
\hline Specific gravity & 2.64 & 2.65 \\
Clay fraction $(<5 \mu)$ & $0 \%$ & $0 \%$ \\
Silt fraction & $20.5 \%$ & $2.5 \%$ \\
Sand fraction & $76.5 \%$ & $94.0 \%$ \\
Gravel fraction & $3.0 \%$ & $3.5 \%$ \\
Maximum grain size & $9.52 \mathrm{~mm}$ & $14.5 \mathrm{~mm}$ \\
Uniformity coefficient & 15.4 & 2.5 \\
\hline
\end{tabular}

was $2 \mathrm{~m}$ square in plan and $1.2 \mathrm{~m}$ depth, and the materials were contained to the height of $1.05 \mathrm{~m}$ from the bottom of the pit. Two kinds of soil were used in the experiment, termed "sandy loam" and "sand", respectively. Their physical properties are described in Table 1. The optimum moisture content of the sandy loam was $11.8 \%$ approximately at which the model ground was compacted. On the other hand, the sand was compacted most densely.

The universal type of loading apparatus was 


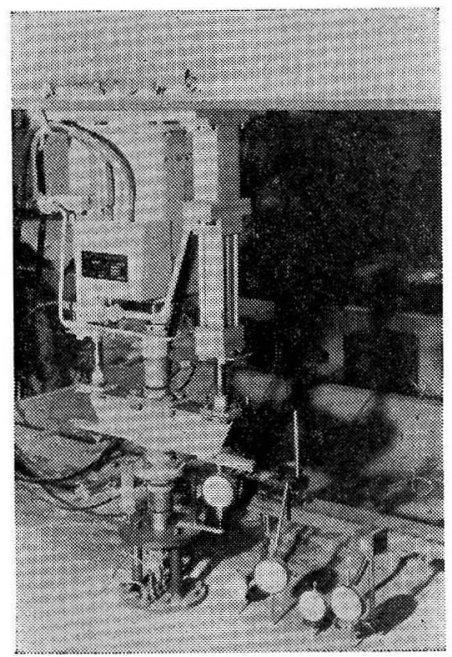

Photo. 1 Dynamic loading apparatus.

used in this model test (Photo. 1). This is operated by oil pressure with a unique loading system of which mechanism has been described in some detail elsewhere. ${ }^{2)}$ The apparatus consists of a vibrator and two cylinders for static load. The former is capable to apply the maximum load of $500 \mathrm{~kg}$ and the latter the maximum load of $1000 \mathrm{~kg}$ by each cylinder so that the maximum applied load amounts to $2500 \mathrm{~kg}$ by the whole loading system. The stroke of pistons is $10 \mathrm{~cm}$. Besides this universal type of apparatus an oil jack with the capacity of 50 tons was used to apply a static load in researching the ultimate bearing capacity of soil ground.

Three kinds in the size of loading plate were used; the diameter of $10 \mathrm{~cm}, 20 \mathrm{~cm}$ and $30 \mathrm{~cm}$. Excepting that of $10 \mathrm{~cm}$-diameter, the distribution of contact pressure was measured as well as stress distribution in the ground.

Load cells were used to measure the load, while

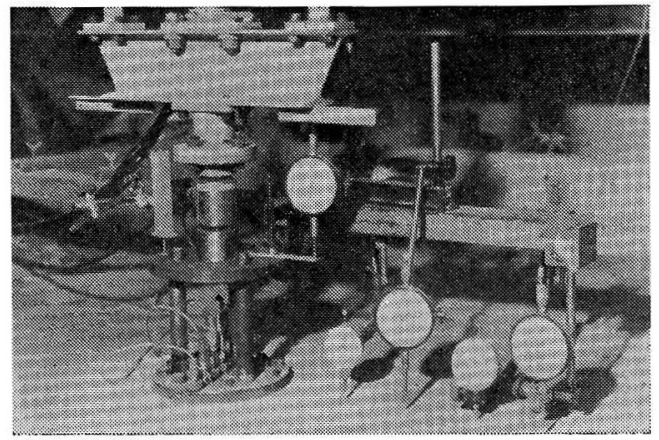

dial gauges and linear variable differential transducers were instrumented for measuring the settlement of loading plates as well as the displacement of soil surface around the loading plates (Photo. 2).

The measurement of stress in the soil ground was done by using the pressure cell of $2 \mathrm{~cm}$ diameter and $3 \mathrm{~mm}$ thickness, whereas four earth pressure meters were used to pick up the contact pressure. These were the semi-conductive type pressure cells and connected to recorders through balance units.

\section{(2) Test Procedure}

The experiment is divided into two series of test: one is the loading test for finding the stress distribution in soil and another is the loading test for finding the ultimate bearing capacity of ground.

In the test series for finding the stress distribution in soil, two kinds of the loading plate with diameter $2 a=10 \mathrm{~cm}$ and $20 \mathrm{~cm}$ were used for sandy loam. In using the former the stress distribution was measured at the depth $z=0.5 a, a$ and $2 a$, and at the distance from the centre of the loading plate $r=0,0.6 a$ and $a$. In using the latter, on the other hand, the distribution of contact pressure was also measured in addition to above-mentioned stress in soil. For sand the stress distribution in soil was measured at the depth $z=1 \mathrm{~cm}, 0.5 a, a, 2 a$ and $3 a$, as well as the contact pressure.

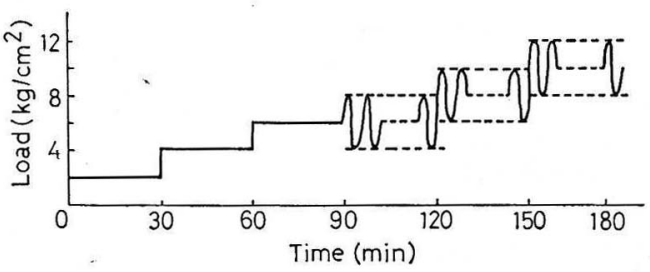

Fig. 2 Loading program in the dynamic test.

In the test series for obtaining the ultimate bearing capacity of ground, the static and dynamic loading procedures were adopted. In the static test one step load of $2 \mathrm{~kg} / \mathrm{cm}^{2}$ was loaded on sandy loam with an interval of $30 \mathrm{~min}$. For sand, on the other hand, the step load was determined as $0.5 \mathrm{~kg} / \mathrm{cm}^{2}$. A loading program showing in Fig. 2, for example, was adopted in the dynamic test.

Photo. 2 Measurement of surface settlement. 


\section{EXPERIMENTAL RESULT}

\section{(1) Distribution of Contact Pressure}

Fig. 3 indicates an example of test results for the distribution of contact pressure measured by pressure cells embedded beneath the loading plate for the case of sandy loam. In this figure the ordinate is normalized as the ratio of the earth pressure $\sigma$ to the load intensity $q$. It is known from this figure that the pressure distribution becomes more uniform as the load increases. In this series of test the investigation was also done on the effect of repeated load, in which unloadings were performed for each step of $1 \mathrm{~kg} / \mathrm{cm}^{2}$ load increase. In the virgin loading, moreover, the pressure at the fringe of loading plate increases with increase in the load intensity, showing the distribution similar to Boussinesq's elastic solution. In the repeating loading, on the other hand, the fringe pressure decreases parabolically at lower load level.

In sandy ground the distribution of contact

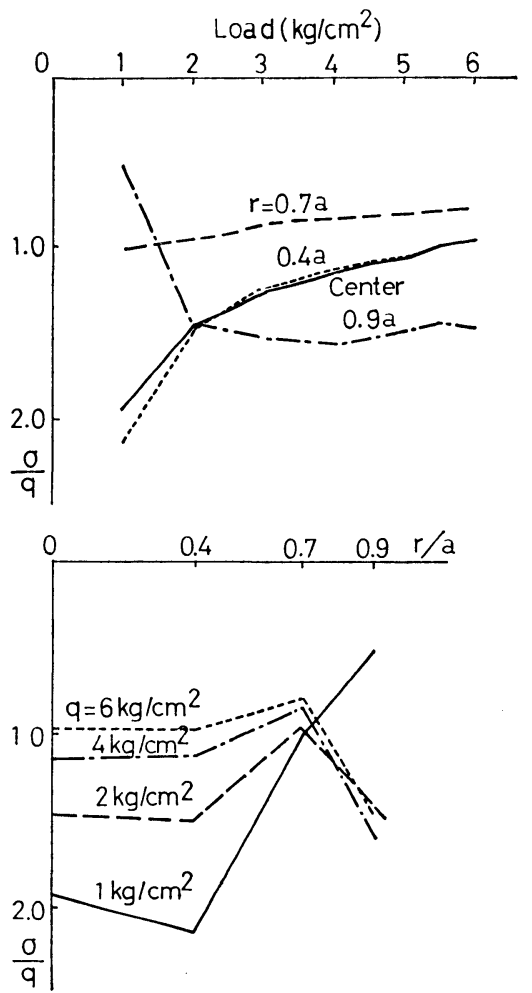

Fig. 3 Distribution of contact pressure for sandy loam. pressure is uniform at lower load level. As the sand does not have cohesion, however, the fringe pressure decreases remarkably at higher level near the ultimate load, thus the stress concentration occurring beneath the centre of loading plate. Such a phenomenon can be seen in Fig. 4 .

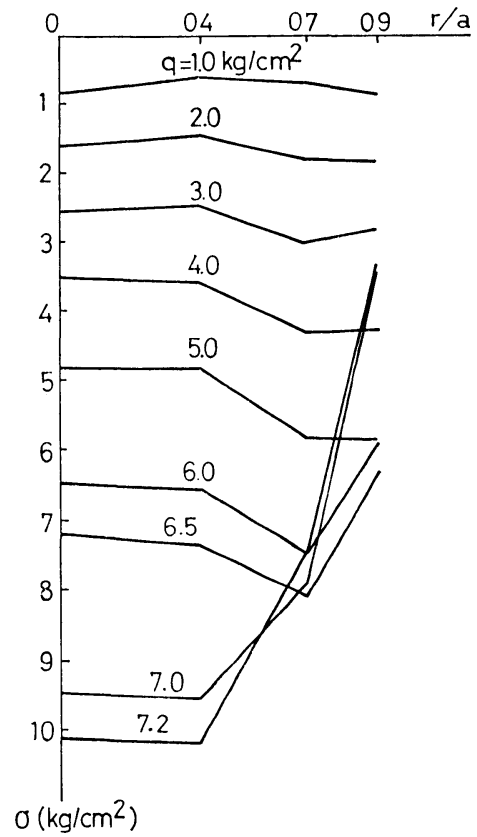

Fig. 4 Distribution of contact pressure for sand.

\section{(2) Stress Distribution in Soil}

In the shallow depth until $z \fallingdotseq 0.5 a$ for sandy loam, the stress distribution varies with load intensity due to the influence of yielding at the fringe of loading plate. At larger depth than $z=a$, however, there does not occur such a variation in stress distribution with load intensity; the tendency of uniform distribution proceeds. For sand, on the other hand, one sees parabolic stress distribution at any depth, as shown in Fig. 5 for the depth $z=0.5 a$. That is, reaching the ultimate load, the stress decreases at the fringe of loading plate and concentrates remarkably beneath the central part. At $z<a$, in particular, the stress of central part exceeds twice the load intensity at the instant of failure. These characteristics indicate that the sandy loam makes only partial ground failure, while general shear failure occurs till the depth of $z=a$ for sand. It can be concluded, therefore, the effect of cohesion is very remarkable on the failure pattern of ground. 


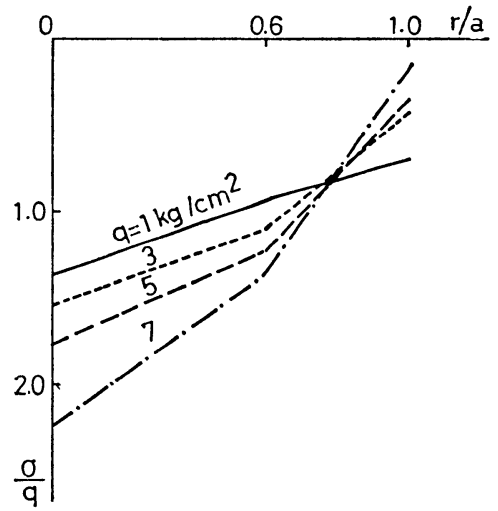

Fig. 5 Static stress distribution in sand $(z=0.5 a)$.

\section{(3) Settlement Characteristics of Loading Plate}

1) Settlement-time curve

Fig. 6 shows the settlement-time curve in the static loading test for sandy loam using a loading plate of $10 \mathrm{~cm}$ diameter. The curve can be divided into three parts. The first corresponds to the small intensity of load till $q=6-8 \mathrm{~kg} / \mathrm{cm}^{2}$ where the settlement occurs simultaneously with load-

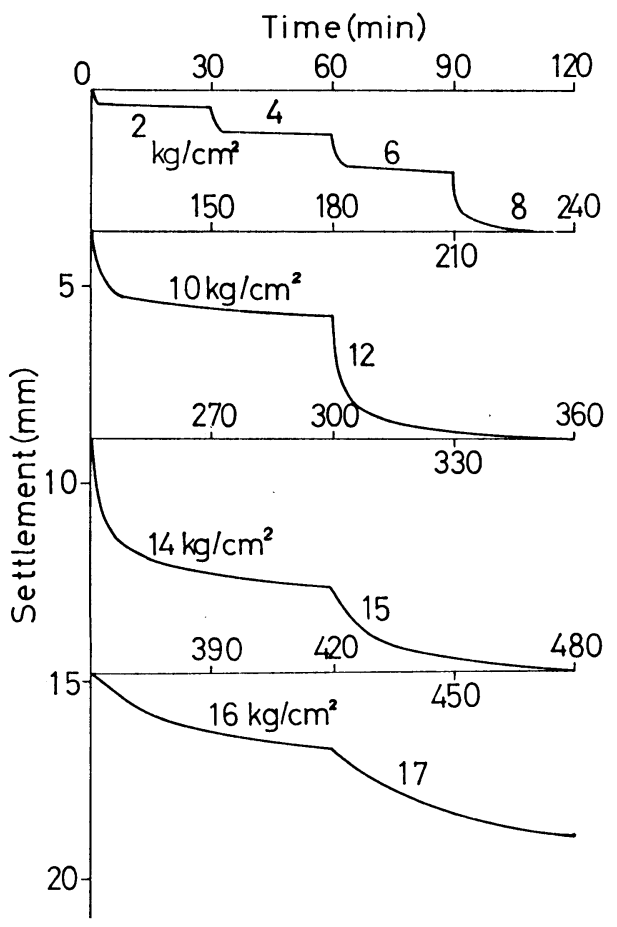

Fig. 6 Settlement-time curve (static) for sandy loam $(a=5 \mathrm{~cm})$. ing. At this stage the ground is in the state of elastic equilibrium; there appears no or very little plastic region in the ground.

The loading stage of $q=8-12 \mathrm{~kg} / \mathrm{cm}^{2}$ is the second part of settlement-time curve where a large settlement can be seen at the instant of loading, followed by a creep strain. In this stage the ground behaves viscoelastically in some region, and there appears the plastic region in an extent of ground, spreading widely with increase in loading. The third part corresponds to the loading larger than $q=12 \mathrm{~kg} / \mathrm{cm}^{2}$. In this stage there occurs no remarkable settlement at the instant of loading, but the time curve shows continuous rate of settlement for 10-20 minutes after loading. The large extent of ground behaves plastically and, therefore, the plastic flow occurs everywhere.

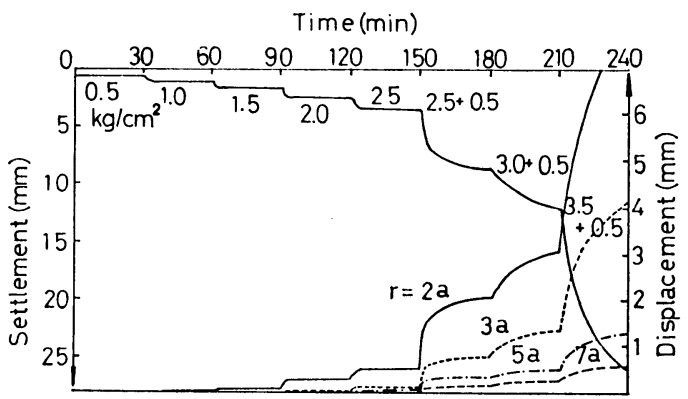

Fig. 7 Settlement-time curve (dynamic) for sand $(a=10 \mathrm{~cm})$.

Under the dynamic load for sand ground the situation is expressed by Fig. 7. The diameter of loading plate is $20 \mathrm{~cm}$ and the oscillatory loading with the frequency of $5 \mathrm{cps}$ is applied after the load intensity of $2.5 \mathrm{~kg} / \mathrm{cm}^{2}$. Refering this figure, one can see a sudden settlement simultaneously after dynamic loading; such a tendency is much remarkable at high frequency. It is understood that the development of plastic region which is unstable under static loading can be easily accelerated by giving dynamic load.

2) Load-settlement curve

Fig. 8 shows the load-settlement curve for sand with some different rates of loading. It is known that there appears stress reduction at higher rate of loading, resulting in the entire failure of ground.

The characteristics of displacement of sand ground at the surface points outside of the loading plate is shown in Fig. 9. Each points indicate heaving up. One can suppose that the plastic 


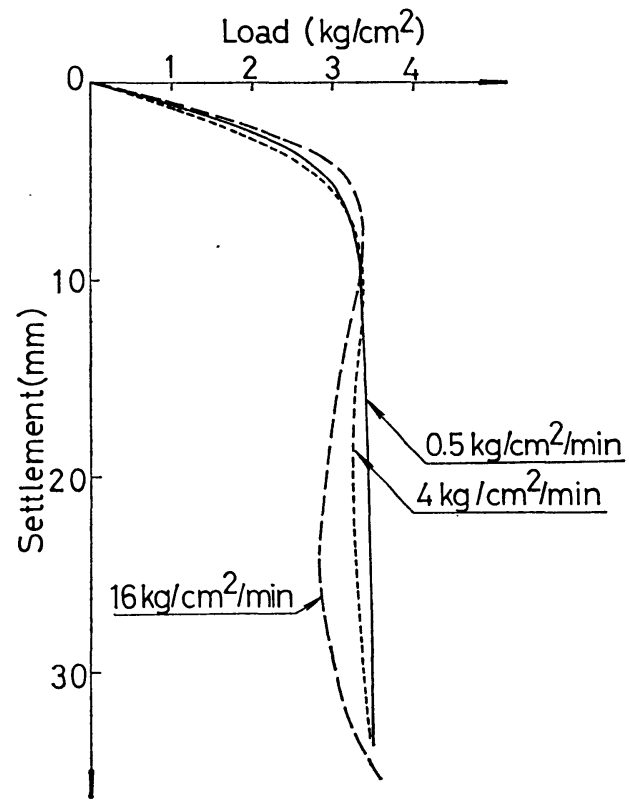

Fig. 8 Effect of rate of loading on the shape of load-settlement curve for sand.

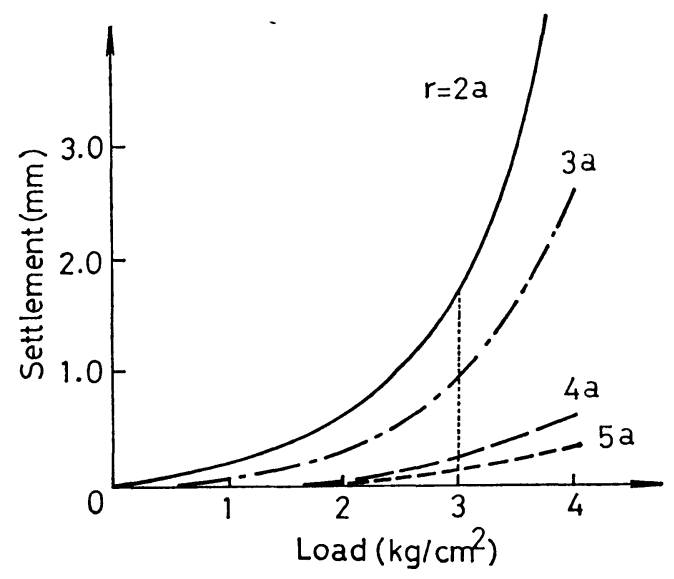

Fig. 9 Displacement of sand grain at the ground surface.

flow occurs at the neighbourhood of the rim of loading plate.

The load-settlement curve for sand under the dynamic load which corresponds to the settlementtime curve in Fig. 7 is illustrated in Fig. 10 with the heaving characteristics of surface points. Large amount of settlement is recognized even at lower stage of loading and the displacement of side points shows gradual increase with the load. This tendency is remarkable at higher frequency.
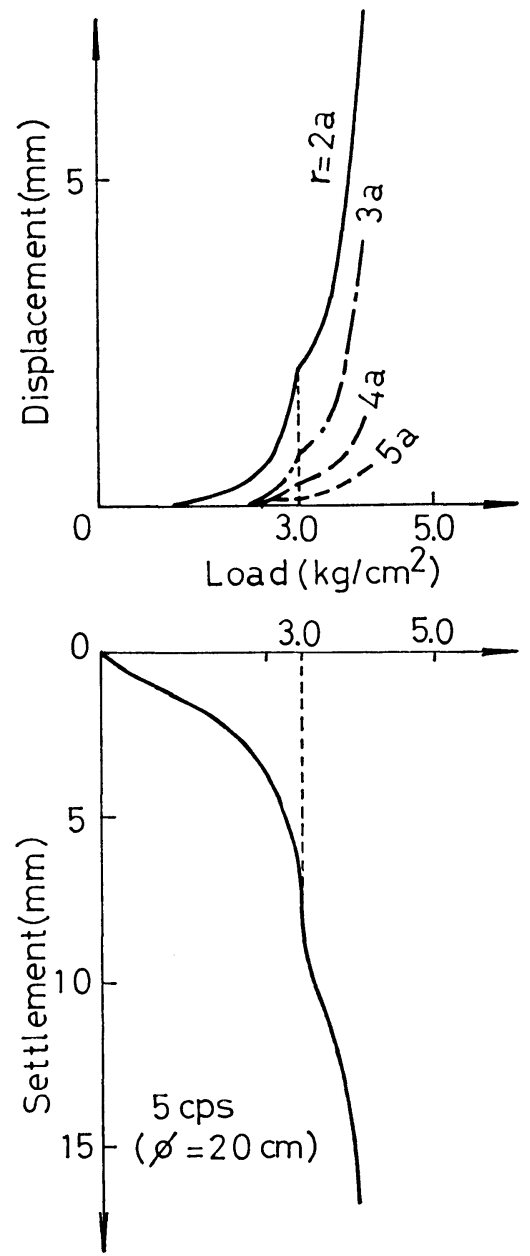

Fig. 10 Load-settlement curve and loaddisplacement curve for sand under dynamic load.

\section{(4) Ultimate Bearing Capacity}

The logarithmic plotting of the load-settlement curves previously mentioned is shown in Fig. 11 for sandy loam. Such a plotting has been originally used in order to obtain the bearing capacity of pile foundation in clayey soil. Two sets of break points appear on each curves which correspond to different diameters of loading plate. The first is considered as the point at which the load-settlement relationship loses its linearity, whereas the second point may correspond to the limiting value where the local plastic region begins to grow beneath the loading plate. In other word, it is supposed that the first points correspond to the yield points where the ground changes 


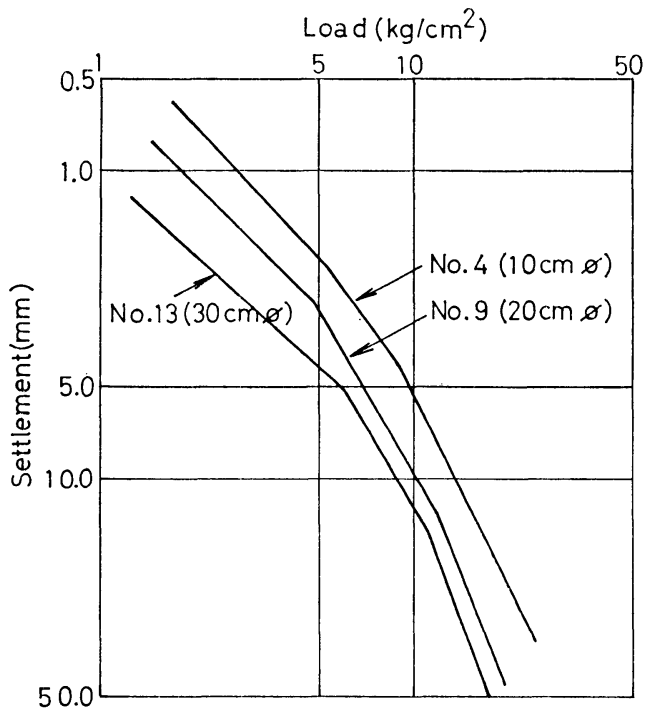

Fig. 11 Logarithmic plotting of load-settlement curves for sandy loam.

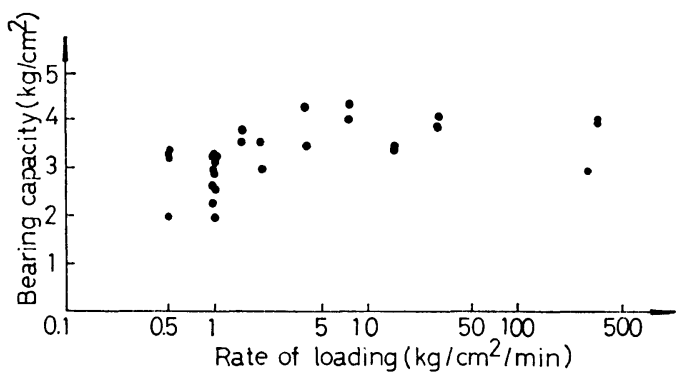

Fig. 12 Correlation between the bearing capacity of sand and the rate of loading.

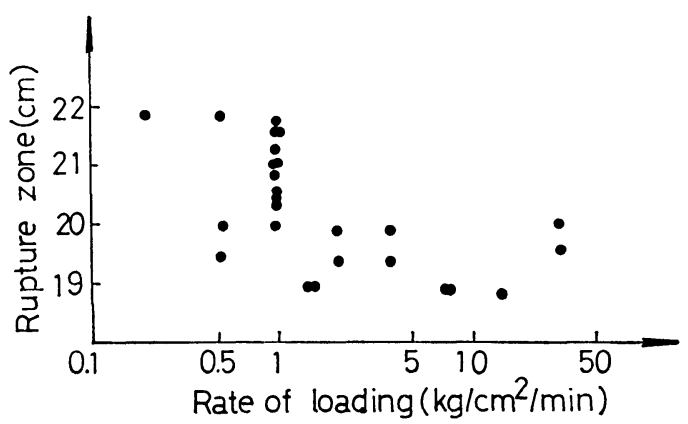

Fig. 13 Correlation between the spreading radius of the rupture zone for sand and the rate of loading.

the behavior from the elastic state to the plastic one, while the second points to the ultimate bearing capacity.
Fig. 12 indicates the correlation between the bearing capacity of sand and the rate of loading, whereas Fig. 13 is the relationship between the spreading radius of the rupture zone that appears on the ground surface and the rate of loading. This radius of rupture zone was measured by scaling the heaved or cracked area surrounding the loading plate. From these figures it can be said that, with increase in the rate of loading, the increase in the bearing capacity of ground and decrease in the area of rupture are recognized.

In closing, the local shear failure is seen in sandy loam whereas the general shear failure is the character for sand, as the general pattern of ground failure investigated.

\section{ELASTO-PLASTIC ANALYSIS BY FEM}

\section{(1) Application of FEM to the Model Test}

A soil medium in the test pit described before was divided into 153 ring elements with triangular cross section. The diameter of loading plate was $20 \mathrm{~cm}$ and, because of the capacity of the digital computer used (FACOM 230-60), it was assumed that there occurred no displacement at the distance of $60 \mathrm{~cm}$ from the centre of the loading plate, both directions in horizontal and vertical. As the boundary condition a forced displacement was given at the base of loading plate. The computation was based on the incremental load process with the modified elastic modulus. ${ }^{3}$ ) Thus, the elasto-plastic analysis could be performed by using the non-linear stress-strain relationship of the soil constituting ground and Mohr-Coulomb's failure criterion.

The deformation modulus of sandy loam was determined as the initial tangent of the stressstrain curve in the unconfined compression test.

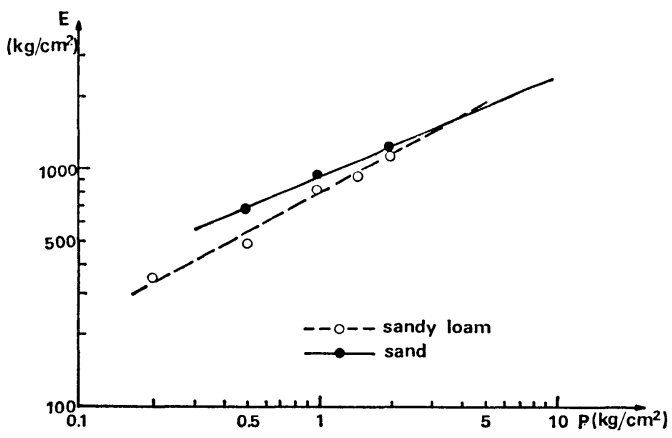

Fig. 14 Relationship between the deformation modulus and the confining pressure. 
As to the effect of confining pressure on the deformation modulus, the relationship is shown in Fig. 14 as the result of triaxial compression test. In the loading test the horizontal stress in the soil medium may correspond to the confining pressure in the triaxial test. This horizontal stress can be divided into two components. One of them is concerned with the own weight of soil, and another is refered to the applied load.

In the actual loading test, however, the former which corresponds to the earth pressure at rest is quite small in the test pit as high as about $0.1 \mathrm{~kg} / \mathrm{cm}^{2}$. On the other hand, the latter can take any value according to the intensity of applied load. On the present stress analysis by FFM the initial value of the deformation modulus $E_{0}=90 \mathrm{~kg} / \mathrm{cm}^{2}$ is adopted for the small amount of lateral pressure for sandy loam. As to the sand material, the half value of that for sandy loam, i.e., $E_{0}=45 \mathrm{~kg} / \mathrm{cm}^{2}$ is taken, since the modulus of sand obtained by the loading test is about half of that for sandy loam.

Based on the result of unconfined compression test it has been found that there exists an approximately linear stress-strain relationship under the stress level of about $70 \%$ of the peak strength. Therefore the above initial deformation modulus is used until where the degree of looseness $R^{*}$ explained below reaches $70 \%$. The failure envelope was obtained by the triaxial test and the direct shear test. The results are summarized in Table 2.

Table 2 Deformation modulus and shear strength parameters of soil materials

\begin{tabular}{c|c|c}
\hline & Sandy loam & Sand \\
\hline \begin{tabular}{c|c} 
Deformation modulus \\
$E_{0}\left(\mathrm{~kg} / \mathrm{cm}^{2}\right)$
\end{tabular} & 90 & 45 \\
\hline $\begin{array}{c}\text { Angle of internal fric- } \\
\text { tion } \phi\end{array}$ & $\begin{array}{c}32^{\circ}\left(\sigma \leq 5 \mathrm{~kg} / \mathrm{cm}^{2}\right) \\
14^{\circ}\left(\sigma>5 \mathrm{~kg} / \mathrm{cm}^{2}\right)\end{array}$ & $44^{\circ}$ \\
\hline Cohesion $c\left(\mathrm{~kg} / \mathrm{cm}^{2}\right)$ & $0.3\left(\sigma \leq 5 \mathrm{~kg} / \mathrm{cm}^{2}\right)$ & 0.016 \\
\hline
\end{tabular}

The inelasticity of soil under loading was expressed by the degree of looseness $R^{*}$, defined as the ratio of the distance $a$, to the failure envelope, and the radius $b$ of the Mohr's stress circle, as shown in Fig. 15. The initial modulus $E_{0}$ and the initial Poisson's ratio $\nu_{0}$ were used when $R^{*}=0$, while as $R^{*}$ increased the modulus decreased rapidly and Poisson's ratio approached 0.5. The values adopted in the numerical analysis are indicated in Fig. 16.

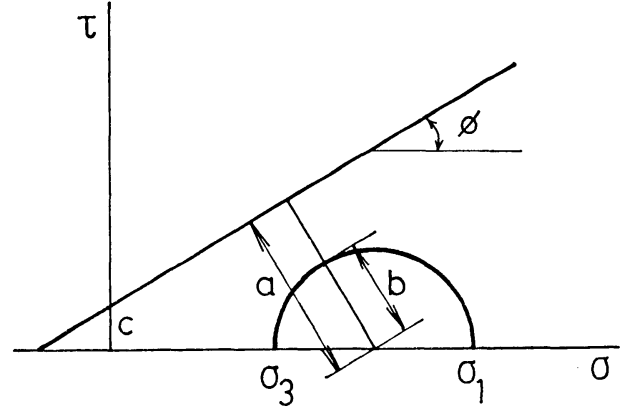

Fig. 15 Definition of the degree of looseness $R^{*}$.
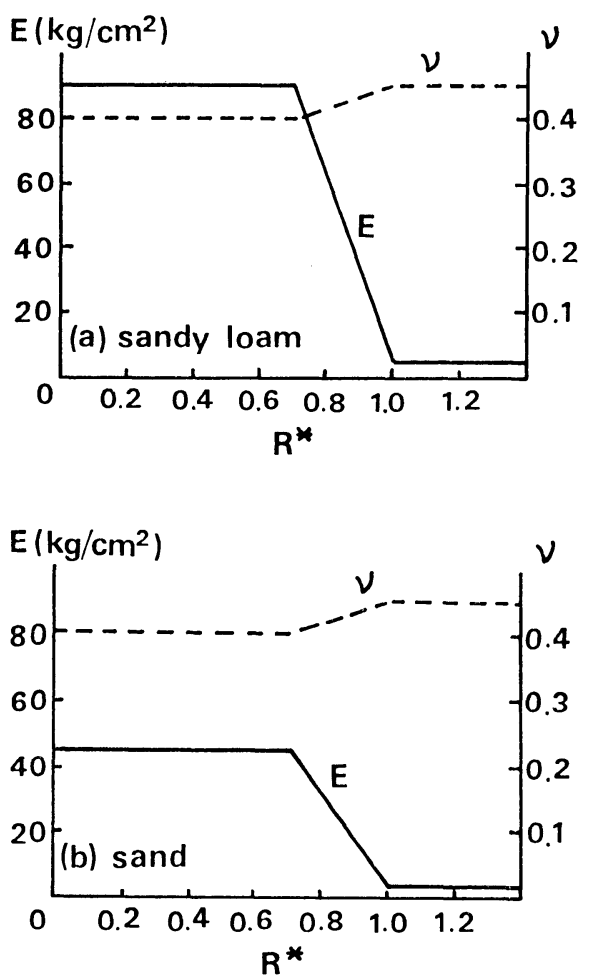

Fig. 16 Relationship between the deformation modulus $E$ as well as Poisson's ratio $\nu$ and the degree of looseness $R^{*}$.

\section{(2) Result of Computation}

In computing the stress distribution in the model ground each amount of settlement was taken as $0.2 \mathrm{~mm}$ or $0.4 \mathrm{~mm}$. An example of computed results for sandy loam is illustrated in Fig. 17. In this figure the black zone indicates the plastic region $\left(R^{*}=1\right)$ and the shaded zone corresponds to the inelastic region where the degree of looseness $R^{*} \geq 0.7$. 


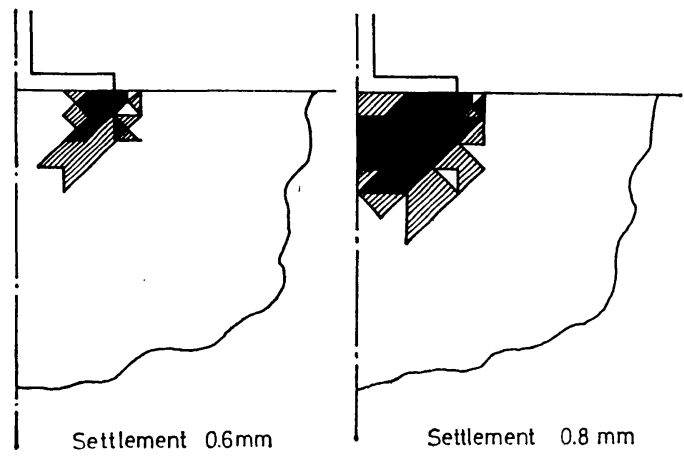

Fig. 17 Development of the plastic region in sandy loam with increase in load.

The development of the plastic region directs toward the central part from the rim of loading plate, as known from Fröhlich's theory.4) Under a plasticity load the plastic regions intercourse with each other on the symmetric axis, and there exists small inelastic region under the bottom of loading plate. At this stage the intensity of load coincides with that of the plasticity load defined by Hoshino ${ }^{5}$; it corresponds to the point of inelastic part on the load-settlement curve. More increase in displacement results in a gradual spreading of the plastic region.

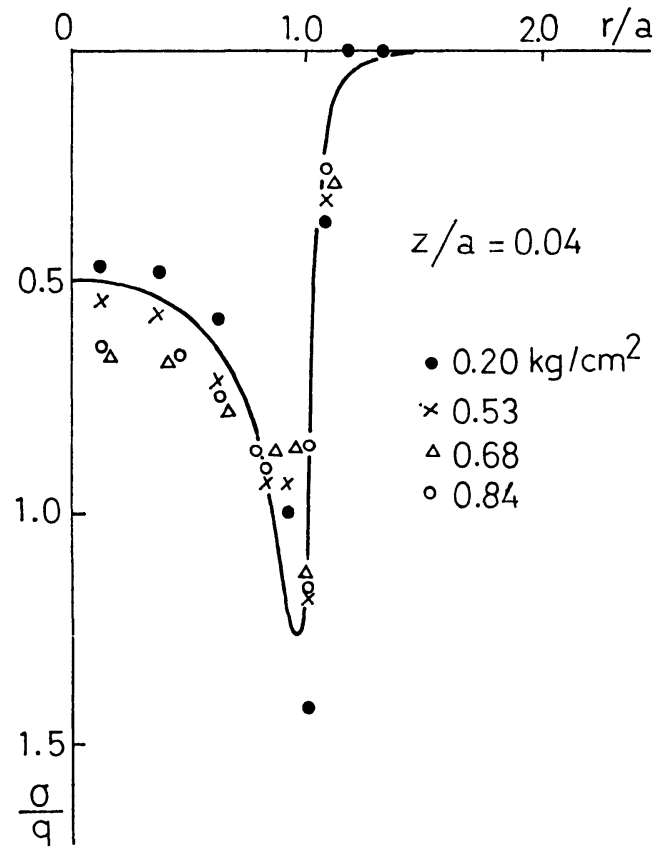

Fig. 18 Computed stress distribution by FEM (sandy loam, $z=0.04 a$ ).
Fig. 18 shows the stress distribution of the sandy loam ground for the depth of $z=0.04 a$ ( $a$ : the radius of loading plate). The solid line indicates the elastic solution for the semi-infinite body. Since the load intensity of first stage $q=$ $0.20 \mathrm{~kg} / \mathrm{cm}^{2}$ is also based on the assumption of linear elasticity, one can know the precision of FEM calculation from this figure. In general the both calculation results coincide with each other at larger depth $z \fallingdotseq 2 a$.

\section{DISCUSSIONS AND CONCLUSIONS}

A series of model tests on the stress distribution and the bearing capacity of soil ground and, based on the experimental results, elasto-plastic analyses with respect to development of the plastic region beneath the loading plate have been performed. Some discussions and conclusions can be summarized as follows.

(1) The distribution of contact pressure measured by pressure cells for sandy loam becomes more uniform as the load increases. In sandy ground, on the other hand, the stress concentration occurs beneath the centre of loading plate at higher level of loading. Such a difference may be caused by the effect of cohesion in soil. (2) The effect of cohesion is also very remarkable on the failure pattern of ground, indicating that the sandy loam makes only the local shear failure, while the general shear failure occurs till the considerable depth for sand.

(3) The sandy loam ground behaves viscoelastically in some region, when the load level approaches the ultimate stage, and there appears the plastic region in an extent of ground, spreading widely with increase in load.

(4) Under the dynamic load for sand ground there occurs a sudden settlement simultaneously after dynamic loading, especially at high frequency. The development of plastic region can be easily accelerated by giving dynamic load.

(5) The logarithmic plotting of the load-settlement curve makes two break points. The first corresponds to the yield point where the ground changes the behavior from the elastic state to the plastic one, whereas the second point to the ultimate bearing capacity.

(6) The FEM-analysis based on the theory of elasto-plasticity indicates that the development of the plastic region directs toward the central part from the rim of loading plate. Under a plasticity load the plastic regions intercourse with each other on the symmetric axis, and there exists small inelastic region under the bottom of 
loading plate.

The authors would appreciate the assistance of Messrs. K. Eguchi and J. Ogawa through the experimental work.

\section{REFERENCES}

1) Terzaghi, K.: Theoretical Soil Mechanics, John Wiley and Sons, 1948, pp. 118-120.

2) Akai, K., S. Shiomi and T. Kiuchi: Model Studies on the Stress Distribution in Layered
Soil Systems, Proc. JSCE, No. 185, 1971, pp. 83-94.

3) Zienkiewicz, O. C.: The Finite Element Method in Engineering Science, McGraw-Hill, 1971, pp. 370-374.

4) Fröhlich, O. K.: Druckverteilung im Baugrunde, Springer, 1934, pp. 72-82.

5) Hoshino, K.: Theory of Bearing Capacity of Foundations (in Japanese), Korona-sha, 1948, pp. 102-114.

(Received May, 1, 1973) 